\title{
CASO DE PREDOMÍNIO DO MÉTODO AUDIOLINGUAL NO ENSINO DA LÍNGUA INGLESA: APONTAMENTOS PARA PENSAR ${ }^{1}$
}

\author{
Selmo Ribeiro FIGUEIREDO JÚNIOR
}

\section{Introdução}

Este trabalho trata do relato e de considerações metodológicas acerca de uma aula observada de Língua Inglesa ministrada na sétima série B da Escola Estadual Nilza de Oliveira Pipino, na cidade de Sinop, MT, realizada no dia cinco de maio de dois mil e nove, no período matutino, cuja turma contava com vinte e três alunos.

Nesse dia, o professor lecionou o uso estrutural das expressões there is/are e dos adverbs, além de efetuar tradução de vocábulos, ocasião na qual se evidenciou a predominância de uma abordagem tradicional sob o método audiolingual.

\section{Descrição da aula ${ }^{2}$}

(1) Depois de entrarmos às 07h07min na sala, as primeiras falas entre si dos alunos, enquanto se dirigiam às carteiras, foram referentes aos jogos municipais a que eles assistiram na véspera; alguns reclamando da condução do árbitro de futebol, outros criticando a estética do uniforme de jogo, o que deu azo ao professor pedir a um aluno vestir o uniforme de aula, que, por seu turno, o fez de pronto.

(2) Com a chegada atrasada de um aluno, o professor brincou com a situação, dizendo que não só o menino atrasado, mas todos deveriam "acordar por conta", sem precisar da "mamãe" ou de qualquer pessoa que seja; e quando da chegada atrasada de outro aluno, o professor retomou em paráfrase o que dissera instantes antes.

(3) Em seguida, o professor foi às carteiras verificar se os alunos fizeram a tarefa solicitada em aula anterior. Aos que fizeram ele parabenizou oralmente, antes de dar visto e anotar os nomes em seu caderno de controle. E, como muitos deixaram de fazer (alguns com a alegação de que esqueceram), o professor disse que não havia justificativa por isso, visto que

\footnotetext{
${ }^{1}$ Este trabalho foi concebido no interior da disciplina de Linguística Aplicada ao Ensino da Língua Inglesa, lecionada pela Prof. Ms. Olandina Della Justina, do Departamento de Letras da Universidade do Estado de Mato Grosso - Unemat, campus de Sinop.

${ }^{2}$ Sob o intuito de facilitar as remissões realizadas a partir da seção seguinte, os parágrafos a seguir — que obedecem ao rigor do método descritivista de relato, atinente aos aspectos comportamental, didático, metodológico e pedagógico — estão numerados em sequência.
} 
a aula de Língua Inglesa vinha acontecendo em apenas um dia da semana. Procurando uma forma de lidar com isso, o professor disse que, a partir daquele momento, duas tarefas que não fossem feitas significariam acionar a coordenadora pedagógica.

(4) Na sequência, o professor trabalhou a expressão de valor adverbial how often em algumas frases comutáveis ${ }^{3}$, tais como "How often [listen to music?]" / "[write letters?]" / "[read comics?]" / "[go to disco]" / "[play at the club]" / "[have breakfast]", seguidas pelas respectivas traduções para o português.

(5) À lousa, ensinou também alguns advérbios e outras expressões de tempo: always, usually, sometimes, hardly ever, never, every week, every month, every year, once a week, once a month, once a year, twice a week, twice a year, three times a day, three times a week, three times a month, four times a day, four times a week. Porém, antes de concluir a lição, o professor, motivado pelos burburinhos e gracejos que surgiam na sala, teve de dizer: "Brincadeira é um momento. Falar sério é outro. Deixem a conversa para depois!"

(6) Isso feito, o professor, procurando garantir a aprendizagem dos alunos acerca da lição, lia em voz alta as expressões traduzidas para o português para que os alunos as lessem, por sua vez, em inglês. Fez isso por vários minutos, até constatar, segundo disse, que apenas oito alunos realmente estavam participando como deveriam, e que, dos demais, metade só mexia a boca e metade esperava os outros falarem para, depois, repetirem o que diziam. Ele terminou a lição pedindo aos alunos retomarem-na em casa.

(7) Daí a pouco, o professor começou a trabalhar as expressões there is e there are, já dizendo, de início que - além de serem traduzidas por há (um) e há (mais de um), respectivamente - os termos de cada uma das locuções se invertem quando passarem para a forma interrogativa (is there?; are there?). Isso posto, o professor foi a algumas carteiras para atendimento individual, enquanto um aluno, furtivo aos olhos do professor, pegava o livro "emprestado" de um colega para copiar as respostas prontas.

(8) Nesse instante, algumas meninas ficaram em pé, fazendo com que o professor chamasse, de novo, a atenção da turma. E ao fim de alguns minutos reservados à atividade dos alunos em sala, o professor apresentou a diferença do there desacompanhado do verbo to be, que se traduz para o português lá. Ensinou também, a esse propósito, o advérbio de lugar where e a locução how long.

(9) Faltando pouco para o término da aula, aconteceu de o professor voltar a advertir um aluno, dizendo-lhe que, se continuasse no Nilza ${ }^{4}$ ou não, ele teria de "resolver a vida".

\footnotetext{
${ }^{3}$ Os termos comutáveis estão entre colchetes.

${ }^{4}$ I. e., Escola Estadual Nilza de Oliveira Pipino.
} 
Nesse momento, com a devida licença, dois alunos saíram para ir participar dos jogos municipais que ainda estavam acontecendo. O professor, logo depois, foi à sua mesa pegar o "caderno verde" - que é um tipo de diário no qual os professores relatam o comportamento em geral negativo mas também positivo de alunos — para fazer uma anotação sobre um menino que estava irrequieto. Com a aula chegando a termo, o professor ainda passava às carteiras prestando auxílio, quando ela findou às $08 \mathrm{~h} 54 \mathrm{~min}$.

\section{Apontamentos teórico-metodológica}

Como bem se percebe no parágrafo 3 da seção anterior, que se ocupa da descrição da aula objeto desta discussão, uma conduta própria do método audiolingual, calcado na psicologia behaviorista (CESTARO, 1999, p. 4; TOTIS, 1991, p. 26), fora adotada pelo professor, porquanto ele lançou mão do ato de parabenizar oralmente os alunos que fizeram a tarefa por ele solicitada, o que se configura como reforço positivo a fim de tentar estabelecer uma recorrência desse evento em ocasiões futuras.

No parágrafo 3, há presente o anúncio dado pelo professor de que, se algum aluno deixasse de fazer duas tarefas, a coordenadora pedagógica seria requisitada, o que deixou subentendido à turma que se trataria de uma forma, ainda que moderada, de punição (possibilidade de reforço negativo), revelando mais uma estratégica utilizada pelo método audiolingual.

Caracteres do método de cunho behaviorista perseveram no parágrafo 4, visto que o professor trabalhou de forma estrutural e intercambiável a expressão how often. A respeito desse método, Leffa diz que

o ensino era feito através de pequenos passos, com a aprendizagem gradual das estruturas, que eram apresentadas uma a uma. No audiolingualismo não se aprendia errando. Acreditava-se que quem errava acabava aprendendo os próprios erros (LEFFA, 1988, p. 223; grifo nosso).

Não é diferente o que constatamos no parágrafo 5, haja vista a sua relação com o que Totis (1991, p. 26) diz acerca de uma das principais características do audiolingualismo levantadas por ela: "Há uma seqüência nas estruturas gramaticais, que são aprendidas uma de cada vez", sabendo-se que os itens lexicais e locuções ali relatados podem, a rigor, pertencer à mesma posição do eixo paradigmático do sistema linguístico.

No parágrafo 6, no entanto, existem indícios (ou resquícios) do método da tradução e gramática, com destaque à tradução, pois o professor traduziu para a língua materna todos os termos naquele momento trabalhos, o que, ainda segundo Totis (1991, p. 25), se alinha a uma 
das características do método referido: “A tradução da língua-alvo para a língua materna é um exercício típico.”

Portanto, afora pequenos elementos metodológicos, como o caso do evento da tradução total de constituintes de enunciados — tal qual está mencionado no parágrafo 6 -, e a considerar, ainda, que os parágrafos restantes ( 7,8 e 9) voltam a nos remeter à prática do estudo gradual de estruturas e da "ameaça" à utilização do "caderno verde", que goza de valor já culturalmente punitivo naquele espaço educacional ${ }^{5}$, o fazer pedagógico na aula aqui discutida foi, predominantemente, sustentado pelo método audiolingual.

\section{Considerações finais}

Partindo das considerações referentes à abordagem de ensino posta em execução pelo professor, tomando-a como "uma filosofia, um enfoque, uma aproximação, um tratamento ou uma lida" (ALMEIDA FILHO, 1999, p. 16), um "conjunto de disposições de que o professor dispõe para orientar todas as ações da operação global de ensinar uma língua estrangeira" (ALMEIDA FILHO, 1993, p. 13), ele não apresentou em sua preleção, com efeito, concepções e procedimentos desligados de uma abordagem tradicional.

Semelhantemente, a abordagem de aprender, "caracterizada pelas maneiras de estudar, de se preparar para o uso, e pelo uso real da língua-alvo que o aluno tem como "normais"” (ALMEIDA FILHO, 1993, p. 13), se nos afigurou pouco ativa, visto que os alunos apresentaram-se passivos no processo de aprendizagem, por sinal em razão da falta de serem devidamente incentivados pelo professor.

No tocante às quatro dimensões da operação global de ensino - planejamento de curso, de materiais, de métodos propriamente ditos ou experiências e a dimensão da aferição do processo e do rendimento (ALMEIDA FILHO, 1999, p. 12) - , percebemos que houve preparação prévia da aula, que o material didático se constituiu apenas por uma apostila, que o método utilizado foi mormente audiolingual e que a aferição posta em exercício se restringiu a correções de ordem ortofônica, portanto ao processo.

Ademais, vale assinalar que medidas modernas de intervenção nas abordagens de ensinar e aprender ligadas às abordagens de procedimento humanista e comunicativa estiveram quase que completamente alheias à aula objeto de nossa ponderação. Por isso, atentando-nos a esse ponto, os elementos mecanicistas adotados pelo professor — seja implícita, seja explicitamente reconhecíveis —, pareceu-nos desfavorecer uma aprendizagem

\footnotetext{
${ }^{5}$ Constatamos isso a respeito do "caderno verde" após a observação de seu uso em sala por outros professores também, da mesma escola, a propósito de outras observações.
} 
significativa por parte dos alunos, a despeito de haver mostras, ainda que diminutas, de aprendizagem.

\section{Referências bibliográficas}

ALMEIDA FILHO, J. C. P. de O. "Ensinar e aprender uma língua estrangeira na escola". In: Dimensões comunicativas no ensino de línguas. Campinas, SP: Pontes, 1993. pp. 11-23.

pp. 11-25.

. O professor de língua estrangeira em formação. Campinas, SP: Pontes, 1999.

CESTARO, S. A. M. O ensino de língua estrangeira: história e metodologia. Revista Virtual Videtur, 6. São Paulo: Mandruvá, 1999. Disponível em: http://www.hottopos.com.br/videtur6/selma.htm. Acesso em: 28 mar. 2009.

LEFFA, V. J. "Metodologia do ensino de línguas". In: BOHN, H. I.; VANDRESEN, P. Tópicos em lingüística aplicada: o ensino de línguas estrangeiras. Florianópolis: Ed. da UFSC, 1988. pp. 211-236.

TOTIS, V. P. Língua inglesa: leitura. São Paulo: Cortez, 1991. pp. 25-30. 